\title{
Educational Reform of Tourism English based on Competency-Based Education Model
}

\author{
Jiayi $\mathrm{Wu}$ \\ School of Foreign language \\ Wuhan Business University \\ Wuhan 430056, China \\ arthurwujiayi@hotmail.com
}

\author{
Haijun Wang \\ School of Computer \\ Hubei University of Education \\ Wuhan 430205, China \\ wanghaijun1977@126.com
}

\begin{abstract}
To reveal the current situation of Tourism English teaching and professional skills training in the application-oriented universities, the research on educational reform of Tourism English is presented, which explores a new education model in aspect of professional skills training. In addition, based on constructivism theory and CBE theory, this paper explores the reform of english curriculum in the major of higher vocational tourism from the perspective of training vocational ability.
\end{abstract}

Keywords-Competency-Based Education, Tourism English, educational reform, constructivism

\section{INTRODUCTION}

Along with the positive trend of Chinese tourism industry, domestic tourism developed rapidly with the unique industrial advantages. The tourism industry became more and more demanding for the graduates from tourism major who can communicate with foreign tourists fluently with the high qualification of professional skills and understanding of current situation of domestic tourism development. However, at present, one of the problems in the teaching of Tourism English in the application-oriented universities is lack of professional skills training related to the Tourism English Course. As a mandatory course in tourism major, Tourism English teaching is quite different from Collage English in terms of functional positioning [1]. Besides the basic English knowledge and skills, it is more important to develop students' knowledge, skills, affection, attitude and values directly related to the work of tourism in Tourism English teaching. This is we called professional skills, which distinguishes Tourism English and Collage English. In the practice of Tourism English teaching, teachers emphasize more on the knowledge delivering not skills training; more on the exams not qualifications, which did not stress the feature of application-oriented education. Therefore, it is a kind of cramming method of teaching in Tourism English course, which restrains students' enthusiasm and initiative, because students can only receive knowledge passively without enough practice in class. This outdated teaching model ignores student's individuality that makes the class lack in liveliness and interaction between teacher and students which cause an ineffective teaching result. The students can hardly communicate effectively and properly with different people on different occasions with gained knowledge and skills under the outdated teaching method.

According to the reason mentioned above, the paper aims to reveal the current situation of Tourism English teaching and professional skills training in the application-oriented universities through the research on educational reform of Tourism English, which takes the matter from the professional skills in the course of Tourism English. Also, it attempts to explore a new education model in the perspective of professional skills training, based on the theories of Constructivism and Competency-Based Education. The paper adopts literature survey method, interview method and questionnaire investigation method in order to explore the reform of Tourism English teaching in application-oriented universities along the path of raising problems, analyzing problems and solving problems.

\section{REGULARITIES OF TOURISM ENGLISH TEACHING REVEALED BY CONSTRUCTIVISM THEORY}

The reform of Tourism English teaching was based on the theory of Constructivism, which was a new teaching approach introduced in the late $80 \mathrm{~s}$ and early $90 \mathrm{~s}$ of 20th century [2]. Constructivism believed that learning was a process of obtaining knowledge. And learners could not gain knowledge by the delivery of lecturers, but by the construction of meaning with the help of lecturers and learning partners, utilizing required learning materials, under a specific social-cultural context. Constructivism advocated that learning should be students-orientated with the instruction of teachers and teachers should emphasize more on the students' enthusiasm, initiative and creativity, making students construct knowledge through exploration and discovery and pay more attention on critical thinking and skills practicing. It also emphasized that learners were the cognitive subject and teachers did not play a role of delivering and cramming but should be the helper and motivator of the construction of meaning. Students were not the receiver of exterior incentives or the object of cramming, but the subjects and the meaning constructors to wrought information. 
Competency-Based Education is a vocational education model, taking the matter of required qualifications for a specific job, to identify training objective, plan teaching content, method and process, and assess the teaching effect [3]. It emphasized the learners' leading position with the core of actual professional skills in a working position based on the fully analysis of occupational roles and professional skills required by industry and society. CBE theory focused on the training of students' skills, especially the professional skills with a more open and flexible teaching approach which transit from teaching-orientated to learning-orientated [4].

\section{THE CONTENTS AND STRATEGIES OF TOURISM ENGLISH REFORM IN APPLICATION-ORIENTED UNIVERSITIES}

\section{A. Training the students' professional skills with Communicative Approach}

Communicative Approach, also called Functional Approach or Notional Approach, was formed with the theory of linguists Hymes and Haliday in 1970s which became the most influenced philosophy all over the world. Communicative Approach believes that the purpose of language teaching is to train the students' communicative skills. Language teaching includes not only language structure but also useful expressions in different context. Communicative Approach emphasizes the training of the students' language ability; encouraging students get access to and practice foreign language frequently with real and veritable language materials which combines sentences with contexts.

In the class with Communicative Approach, the final purpose of the communicative activities is the improvised language input and output. During the whole teaching procedure, Communicative Approach does not limit in the inter-communication, however, it focus on the fusion of designed context and textbook in class. With immense different types of language input, it makes students utilize the acquired language knowledge properly and transform the language knowledge into skills through communicative activities. Communicative activities could be role play, group discussion, problem-solving task, presentation, as well as situational dialogue.

For instance, in the teaching process of Simulated Tourism English, the teacher designed 9 tasks including Meeting visitors, Conducting a bus tour guiding, Check-in and check-out at a hotel, Making tour plans, Establishing a good working relationship, Handling complaints, Making a good tour commentary, Introducing Chinese cuisine, Managing problems and Farewell. In each task, students will be assigned to play different roles in order to make a situational dialogue. Sometimes, the teacher will provide a difficult problem for the students to discuss like how to deal with an angry customer at a restaurant? In this way, students can improve their comprehensive skills of foreign language communication, critical thinking, analyzing, and tour guiding as well as the skills of dealing with emergencies.

\section{B. Adapting multimedia approach to train students' professional skills}

The adaption and development of multimedia technology make the Constructive Approach philosophy implement thoroughly in Tourism English teaching procedures, which advocate that students are the subject in the learning process with the instruction of the teachers. It can fully activate students' learning enthusiasm and initiative, improve students' creativity and increase learning efficiency dramatically. Comparing with Collage English, Tourism English enjoys features as more class activities, more communication context and more language materials. During the multimedia teaching process, the teacher help students understand with the movements of pictures and kinds of animations. Besides various multimedia teaching materials, teachers can choose audio-visual materials related to the textbook or teaching content. Moreover, the teacher and the students can record their training performance in scenic spots or other training base as a model for future learning. Teachers can design different situation with multimedia technology, creating a favorable communication environment which makes students improve their language expressions, widen their view and strengthen their language sense in a more real language context through language training in class communication activities. In a word, with multimedia technology, teaching process could be more lively and efficiently. In addition, multimedia technology can provide pictures, videos, warning tones and background music in all kinds of teaching activities in order to build a favorable learning atmosphere. It not only increases the teaching capacity, but also improves the information input, which is beneficial for expanding students' knowledge and vision. For example, teachers can show videos about cultures and customs in different countries which can enrich students' experience as well as the understanding of the text. Thus, teachers can pay more time on instructing individuals which can strengthen the training level with multimedia devices in order to consolidate the training performance and implement intensive language practice activities.

\section{Adopting a procedure-result mixed assessment to train students' professional skills}

Procedure-result mixed assessment focus on both learning procedure and result. It is more students oriented than the traditional assessment that focus only on final exam, which pay more attention to students' personality. It is beneficial for inspiring students' emotion, willpower and attitude, which can lead a positive effect to the class lecturing. As traditional assessment overemphasizes the function of examining and distinguishing, it ignores the function of improving and motivating as well as the assessment of students' professional skills. Because professional skills training is a kind of process, emphasizing procedure assessment can take effect in order to monitor and instruct students when they are not highly autonomic. 
As an applied and practical course, Tourism English emphasizes a philosophy of students-oriented. Students have much more opportunities to take part in performance and presentation than other courses. Therefore, teachers should keep eyes on studen ts' procedure of searching, exploring and hard-working. Unless teachers can recognize students' improvement at different steps and problems chronically, they can provide effective instruction to help students develop continuously which will realize the function of improving through assessment. Therefore, assessment of Tourism English could be divided into two parts --- regular grade and final exam, in which regular grade is the assessment of the learning procedure. In order to reflect the truly situation of professional skills mastering, assessment should consider teachers' opinion and team members' opinion as well as self-assessment. Teachers mainly assess students' attitude, participation and task achievement like attendance, presentation, class performance, assign ments, and written and oral tests. Meanwhile, teammates can assess one team member according to one's performance in the team. The emphasis of regular grade can motivate students' willing of class performance and learning initiative.

TABLE I. PROFESSIONAL SKILLS ASSESSMENT CHART

\begin{tabular}{|c|c|c|c|c|c|}
\hline \multicolumn{2}{|c|}{ Final Exam (60 points) } & \multicolumn{2}{c|}{ Regular Grade (40 points) } & \multirow{2}{*}{ Total Score } \\
\hline Written Test & Oral Test & Self-assessment & $\begin{array}{c}\text { Teammates' } \\
\text { Assessment }\end{array}$ & $\begin{array}{c}\text { Teacher's } \\
\text { Assessment }\end{array}$ & \\
\hline 30 points & 30 points & 5 points & 5 points & 30 points & 100 points \\
\hline
\end{tabular}

TABLE II. STATISTIC OF TEACHING EFFECT

\begin{tabular}{|c|c|c|c|c|c|}
\hline Survey Item & Valid Num & Minimum & Maximum & Mean & Std. Deviation \\
\hline Learning Interests & \multirow{5}{*}{110} & 6 & 9 & 7.57 & 0.96 \\
\hline Learning Initiative & & 7 & 10 & 8.52 & 0.87 \\
\hline Learning effect & & 6 & 10 & 8.73 & 0.76 \\
\hline Professional Skills & & 3 & 8 & 6.28 & 1.42 \\
\hline Application ability & & 5 & 8 & 6.86 & 0.71 \\
\hline
\end{tabular}

TABLE III. ANALYSIS OF TEST

\begin{tabular}{|c|c|c|c|}
\hline Key points & Degree of difficulty & Types & Average score \\
\hline Vocabulary & low & Written test & 18.33 \\
\hline Useful expressions & medium & Written test & 17.57 \\
\hline Communication & high & Oral test & 16.72 \\
\hline Tour guiding & medium & Oral test & 17.65 \\
\hline
\end{tabular}

\section{TRAINING HIGH-QUALITY “DUAL-QUALIFICATION” TOURISM ENGLISH TEACHERS}

As the organizer and instructor during the teaching procedure, teachers should lead the students to the right direction when they are learning. The quality of a teacher dictates whether one could make the positive effect in order to organize and motivate students to complete the learning tasks. Teachers' professional and language capabilities will give direct impact to the teaching effect, so they are the precondition and basic to increase teaching quality. Therefore, in order to reach the teaching objective, it is vital to set up a qualified "dual-qualification" teacher's team. "Dual-qualification" tourism English teacher means teachers with both guiding knowledge and experience and excellent English skill. As Tourism English is a course with application and practice, it is very important to improve teachers' comprehensive skills. Without high-quality "dual-qualification" tourism English teachers' team, it is impossible to reach the learning objective of training students' professional English communicative skills. There are two approaches to strengthen "dual-qualification" teachers' team as follows:

First, for the English major teachers, it is necessary to send them to types of professional tourism training and encourage them to get certificates or guiding experience. After acquiring professional tourism knowledge, English teachers can give more vivid and accurate lectures to students. It is a requirement of teaching development to make English major teachers more professional in tourism. English teachers, only with professional tourism knowledge, can train tourism talents with better English communicative skills.

Second, there are $78 \%$ young teachers in tourism major according to the survey. They just graduated from the universities with qualified English skills. However, they do not need to use English during their daily teaching, which cause a drawback of their English skills. Actually, it is not difficult to train these tourism major teachers to be tourism English teachers. They only need short time systematic training of English skills including listening, speaking, reading, writing and translating. Then they are competent to teach Tourism English. 


\section{CONCLUSION}

Tourism English course is quite different with Collage English in terms of the function. The paper aims to reveal the current situation of Tourism English teaching and professional skills training in the application-oriented universities through the research on educational reform of Tourism English, which takes the matter from the professional skills in the course of Tourism English.

\section{ACKNOWLEDGMENT}

This work was financially supported by a project from the Wuhan Academy of Education Sciences (No.2013A044) and a grant from the Hubei Provincial Department of Higher Education Teaching Reform Research (No.2016419).

\section{REFERENCES}

[1] Li Jing. "Analysis of application for situational teaching method in tourism English teaching," In: Proc. of 3rd International Conference on Information Technology and Career Education (ICITCE), Seoul, South Korea, DEC 24-25, 2015, pp: 1-4.

[2] Liu Hong; Zhao Linping. "Analysis on the Application of Chinese Culture to Tourism English Course Teaching in Colleges and Universities," Advances in Social Science Education and Humanities Research, vol. 55 page: 991-994, 2016.

[3] Covarrubias-Papahiu Patricia. "Teaching Representations of Competency- Based Education: A Case Study,” Propositos Y Representaciones, vol. 4 issue 2, page: 105-132, JUL 2016.

[4] Castaneda Fernandez J. "New educational Degree programs based on competences and adapted to the European Higher Education Area (EHEA) development analysis,” Redu-Revista De Docencia Universitaria, vol. 14 issue 2, page: 135-157, JUL-DEC 2016. 